\title{
On the effect of risk aversion in two-person, two-state finance economies
}

Citation for published version (APA):

Berden, C., \& Peters, H. J. M. (2006). On the effect of risk aversion in two-person, two-state finance economies. METEOR, Maastricht University School of Business and Economics. METEOR Research Memorandum No. 011 https://doi.org/10.26481/umamet.2006011

Document status and date:

Published: 01/01/2006

DOI:

10.26481/umamet.2006011

Document Version:

Publisher's PDF, also known as Version of record

\section{Please check the document version of this publication:}

- A submitted manuscript is the version of the article upon submission and before peer-review. There can be important differences between the submitted version and the official published version of record.

People interested in the research are advised to contact the author for the final version of the publication, or visit the DOI to the publisher's website.

- The final author version and the galley proof are versions of the publication after peer review.

- The final published version features the final layout of the paper including the volume, issue and page numbers.

Link to publication

\footnotetext{
General rights rights.

- You may freely distribute the URL identifying the publication in the public portal. please follow below link for the End User Agreement:

www.umlib.nl/taverne-license

Take down policy

If you believe that this document breaches copyright please contact us at:

repository@maastrichtuniversity.nl

providing details and we will investigate your claim.
}

Copyright and moral rights for the publications made accessible in the public portal are retained by the authors and/or other copyright owners and it is a condition of accessing publications that users recognise and abide by the legal requirements associated with these

- Users may download and print one copy of any publication from the public portal for the purpose of private study or research.

- You may not further distribute the material or use it for any profit-making activity or commercial gain

If the publication is distributed under the terms of Article $25 \mathrm{fa}$ of the Dutch Copyright Act, indicated by the "Taverne" license above, 


\title{
On the effect of risk aversion in two-person, two-state finance economies
}

\author{
Caroline Berden* Hans Peters*
}

First version, March 2006

\begin{abstract}
The effect of replacing an agent in a two-person two-state finance economy by a more risk averse agent is studied. It is established under which conditions the other agent benefits or looses in equilibrium from dealing with a more risk averse agent. If one agent becomes more risk averse, then the equilibrium allocation moves towards that agent's certainty line. Whether or not that is beneficial for the other agent, depends on the location of the endowment point.
\end{abstract}

Keywords: Two-person two-state finance economies, risk aversion JEL Codes: D50, D80

\section{Introduction}

The concept of risk plays a central role in financial markets, both in theory and in practice. The celebrated capital asset pricing model, for instance, gives a relation between asset equilibrium prices when - among other conditions - agents' choices are based on a tradeoff between means and variances of assets. An aspect, however, which to the best of our knowledge has received little attention is the effect an agent's risk attitude has on the utility of the other agents in equilibrium. The purpose of this paper is to study this effect

*Department of Quantitative Economics, University of Maastricht, P.O. Box 616, 6200 MD Maastricht, The Netherlands. Tel.: +31 43 3883835, email: c.berden@ke.unimaas.nl, h.peters@ke.unimaas.nl. 
in about the simplest possible model, namely a two-person two-state finance economy.

In such an economy the two agents are equipped with endowments of a single good (e.g., money) in two possible states of the world. These states of the world occur with commonly known probabilities. The agents trade in the two associated Arrow securities and evaluate allocations according to their von Neumann-Morgenstern utility functions. At the equilibrium prices, markets clear - the total allocation per state is equal to the total endowment per state - while agents maximize their expected utility. This is the simplest version of a financial market (see, for instance, LeRoy and Werner, 2001). It is equivalent to a two-person two-good exchange economy with, of course, quite special utility functions.

To facilitate the exposition we assume that the economy has a unique interior equilibrium and then we ask the following question. Suppose an agent is replaced by a more risk averse agent in the sense of the Arrow-Pratt measure of risk aversion: is the new equilibrium allocation better or worse for the other agent? In slightly different wording, does increased risk aversion of one agent benefit or hurt the other agent?

In answering this question, we find that the position of the endowment point is an important factor. If agent $A$ is replaced by a more risk averse agent, then the equilibrium allocation moves towards $A$ 's certainty line, i.e., the line of risk free allocations. This movement takes place along agent $B$ 's offer (demand) curve. If the new equilibrium allocation is farther away from the endowment point than the original one, then $B$ 's utility increases, otherwise it decreases. Only cases where the equilibrium allocation passes the endowment point are ambiguous in terms of change of $B$ 's utility.

As a typical example, suppose the total endowment in state 1 is higher than in state 2 , agent $A$ has a higher endowment in state 1 than in state 2 , and in equilibrium agent $A$ 's allocation in state 1 is smaller than his endowment in state 1 . I.e., he has traded part of his state 1 endowment for state 2 securities. In that case, if agent $A$ is replaced by a more risk averse agent, that agent will demand even more state 2 securities in order to move closer to a risk free allocation. Hence, the equilibrium allocation moves away from the endowment point along $B$ 's offer curve. Such a change is always to the benefit of agent $B$ - intuitively since the endowment point is available whatever the prices are, so moving away from it reveals an increase in utility. This movement is accompanied by a price decrease of state 1 securities. The intuition that agent $B$ benefits from this is tempting, but it should be taken 
with some care since price changes also have income effects. Nevertheless, the situation can be summarized by saying that agent $B$ benefits from a more risk averse agent $A$ demanding a less risky portfolio, resulting in a price decrease of an asset demanded by $B$ and having a positive net effect on $B$ 's utility.

Other cases, collected in the main result Theorem 1 of this paper, can be given similar interpretations. It may not come as a big surprise that it depends on the relative locations of the endowment and the equilibrium whether increased risk aversion of one agent benefits or hurts the other agent. On the other hand, for any possible configuration we can either say what is the case, or spell out why it is ambiguous. Our results are only for two agents and two states, but these can be interpreted as aggregates for two different groups of agents and two different classes of states. See also the concluding section of the paper.

The paper is organized as follows. Section 2 describes the model and some preliminary observations, Section 3 presents the main result, and Section 4 concludes.

\section{Preliminaries}

We consider economies with two agents $A$ and $B$, a single good, and two states of the world. The endowments of the agents are denoted by $e^{A}=$ $\left(e_{1}^{A}, e_{2}^{A}\right)$ and $e^{B}=\left(e_{1}^{B}, e_{2}^{B}\right)$, where the subscripts refer to the states of the world. Throughout, it is assumed that $e^{A}>0$ and $e^{B}>0$, i.e., each agent is endowed with a positive amount of the good in each state. ${ }^{1}$ State of the world 1 occurs with probability $\pi$ and state of the world 2 with probability $1-\pi$. The total endowment in state 1 is denoted by $w_{1}$ and the total endowment in state 2 by $w_{2}$, so $w_{1}=e_{1}^{A}+e_{1}^{B}$ and $w_{2}=e_{2}^{A}+e_{2}^{B}$. The preferences of the agents are expressed by von Neumann-Morgenstern utility functions $u^{A}, u^{B}$ : $[0, m] \rightarrow \mathbb{R}$, where $m \in \mathbb{R}$ with $m \geq \max \left\{w_{1}, w_{2}\right\}$. We assume that these functions are strictly concave, strictly increasing and twice differentiable on the interior of their domain, so $\left(u^{A}\right)^{\prime},\left(u^{B}\right)^{\prime}>0$ and $\left(u^{A}\right)^{\prime \prime},\left(u^{B}\right)^{\prime \prime}<0$. Such an economy is denoted by $\mathcal{E}=\left(u^{A}, u^{B}, e^{A}, e^{B}, \pi\right)$.

Let $p_{1}$ and $p_{2}$ be positive 'state' prices. Given these prices, an agent in the economy with utility function $u$ and endowment $e=\left(e_{1}, e_{2}\right)$ faces the

\footnotetext{
${ }^{1}$ The vector inequality $x>y$ means that every coordinate of $x$ is strictly larger than the corresponding coordinate of $y$.
} 
familiar consumer problem

$$
\begin{aligned}
\max _{x_{1}, x_{2}} \pi u\left(x_{1}\right)+ & (1-\pi) u\left(x_{2}\right) \\
\text { subject to } p_{1} x_{1}+p_{2} x_{2}= & p_{1} e_{1}+p_{2} e_{2} \\
& x_{1}, x_{2} \geq 0 .
\end{aligned}
$$

From our assumptions it follows that this problem has a unique solution, the demand vector $x\left(p_{1}, p_{2}\right)$. It is routine to verify that an interior solution to (1) satisfies

$$
\frac{p_{1}}{p_{2}}=\frac{\pi u^{\prime}\left(x_{1}\right)}{(1-\pi) u^{\prime}\left(x_{2}\right)},
$$

with $x_{1}$ and $x_{2}$ satisfying the budget constraint. As is clear from the budget constraint and also from (2), prices are relative. It will often be convenient to fix the price of state 2 at $p_{2}=1$ and consider changes in $p_{1}$.

A pair $x^{A}, x^{B} \in \mathbb{R}^{2}$ of nonnegative vectors is called an allocation. If, moreover, $x_{1}^{A}+x_{1}^{B}=w_{1}$ and $x_{2}^{A}+x_{2}^{B}=w_{2}$, then the allocation is called feasible. As usual, a (Walrasian) equilibrium in this economy is a vector of positive prices $p=\left(p_{1}, p_{2}\right)$ and a feasible allocation $x^{A}=\left(x_{1}^{A}, x_{2}^{A}\right)$ and $x^{B}=$ $\left(x_{1}^{B}, x_{2}^{B}\right)$ such that $x^{A}$ solves (1) for $A$ and $x^{B}$ solves (1) for $B$. Feasibility implies that markets clear.

A useful instrument to study equilibria is the offer curve. For an agent with utility function $u$ and endowment $e$ in the economy $\mathcal{E}$, the offer curve associates with each price vector $p=\left(p_{1}, p_{2}\right)$ the demand vector $x(p) \in \mathbb{R}^{2}$ which solves problem (1). Clearly and well-known, by (2), the offer curve of an agent passes through the endowment, and in the economy $\mathcal{E}$, a feasible allocation $\left(x^{A}, x^{B}\right) \neq\left(e^{A}, e^{B}\right)$ is part of an equilibrium if and only if $x^{A}$ is on $A$ 's offer curve and $x^{B}$ is on $B$ 's offer curve. When drawn as curves in an Edgeworth box, both the offer curve of $A$ and of $B$ passes through the endowment point $e=\left(e^{1}, e^{2}\right)$ and through each equilibrium allocation $\left(x^{A}, x^{B}\right)$. We will use the expression 'offer curve' also for the corresponding curve in the Edgeworth box.

For later reference we collect some useful observations about offer curves and equilibria. For completeness' sake, all proofs are provided.

The first lemma describes how demand and, thus, offer curves depend on prices.

Lemma 1 Consider an agent in $\mathcal{E}$ with utility function $u$ and endowment e. Let $x_{1}\left(p_{1}, p_{2}\right)$ and $x_{2}\left(p_{1}, p_{2}\right)$ be the demand functions in state 1 and state 2, respectively. Assume interior demand, i.e., $x_{1}\left(p_{1}, p_{2}\right)>0$ and $x_{2}\left(p_{1}, p_{2}\right)>0$. 

(i) If $e_{1}-x_{1}\left(p_{1}, p_{2}\right) \leq 0$, then $\frac{d x_{1}}{d p_{1}}<0 .{ }^{2}$
(ii) If $e_{1}-x_{1}\left(p_{1}, p_{2}\right) \geq 0$, then $\frac{d x_{2}}{d p_{1}}>0$.

Proof. Since prices are relative, it is without loss of generality to set $p_{2}=1$. Then, by $(2)$, for the demand $x(p)$ we have $p_{1}=\frac{\pi u^{\prime}\left(x_{1}\right)}{(1-\pi) u^{\prime}\left(x_{2}\right)}$, with $x_{2}=$ $p_{1}\left(e_{1}-x_{1}\right)+e_{2}$. By straightforward computation,

$$
\frac{d x_{1}}{d p_{1}}=\frac{(1-\pi)\left(u^{\prime}\left(x_{2}\right)\right)^{2}+\pi u^{\prime}\left(x_{1}\right) u^{\prime \prime}\left(x_{2}\right)\left(e_{1}-x_{1}\right)}{\pi\left(u^{\prime}\left(x_{2}\right) u^{\prime \prime}\left(x_{1}\right)+p_{1} u^{\prime}\left(x_{1}\right) u^{\prime \prime}\left(x_{2}\right)\right)} .
$$

This implies (i). For (ii), again by straightforward computation,

$$
\frac{d x_{2}}{d p_{1}}=\frac{\pi u^{\prime \prime}\left(x_{1}\right)\left(x_{2}-e_{2}\right)-p_{1}^{2}(1-\pi) u^{\prime}\left(x_{2}\right)}{p_{1}^{3}(1-\pi) u^{\prime \prime}\left(x_{2}\right)+p_{1} \pi u^{\prime \prime}\left(x_{1}\right)} .
$$

If $e_{1}-x_{1}\left(p_{1}, p_{2}\right) \geq 0$, then by the budget constraint $e_{2}-x_{2}\left(p_{1}, p_{2}\right)=e_{2}-x_{2} \leq$ 0 , so (ii) follows from (4).

An implication of Lemma 1 for the offer curve is given in the following lemma. The lemma says that an agent's offer curve cuts each budget line in two points, namely the endowment point and the demand point: for in-between prices the offer curve is below, and for other prices above the budget line.

Lemma 2 Consider an agent with utility function $u$ and endowment e. Fix the price of state 2 at $1, p_{2}=1$, and denote $x(p)$ by $x\left(p_{1}\right)$. Let $e=x\left(p_{1}^{e}\right)$ and let $q_{1} \neq p_{1}^{e}$ with $x\left(q_{1}\right)>0$. Then:

(i) if $p_{1}$ is weakly between $p_{1}^{e}$ and $q_{1}$, then $x\left(p_{1}\right)$ is affordable at price $q_{1}$, i.e.,

$$
q_{1} x_{1}\left(p_{1}\right)+x_{2}\left(p_{1}\right) \leq q_{1} e_{1}+e_{2} .
$$

(ii) if $p_{1}$ is not between $p_{1}^{e}$ and $q_{1}$, then $x\left(p_{1}\right)$ is not affordable at price $q_{1}$, i.e.,

$$
q_{1} x_{1}\left(p_{1}\right)+x_{2}\left(p_{1}\right)>q_{1} e_{1}+e_{2} .
$$

\footnotetext{
${ }^{2}$ Strictly speaking, these are partial derivatives. Since prices are relative, so that we can always fix the price of one of the goods (states), we use the ordinary derivative notation here and in the sequel.
} 
Proof. Assume without loss of generality that $x_{1}\left(q_{1}\right)<e_{1}$ and (thus) $x_{2}\left(q_{1}\right)>$ $e_{2}$. Lemma 1 implies that $p_{1}^{e}<q_{1}$. To prove (i), let $p_{1}^{e} \leq p_{1} \leq q_{1}$. Then, since $e$ solves (1) at price $p_{1}^{e}$, we must have

$$
p_{1}^{e} x_{1}\left(p_{1}\right)+x_{2}\left(p_{1}\right) \geq p_{1}^{e} e_{1}+e_{2} .
$$

By subtracting this inequality from the equation

$$
p_{1} x_{1}\left(p_{1}\right)+x_{2}\left(p_{1}\right)=p_{1} e_{1}+e_{2}
$$

we obtain the inequality $\left(p_{1}-p_{1}^{e}\right) x_{1}\left(p_{1}\right) \leq\left(p_{1}-p_{1}^{e}\right) e_{1}$, which by $p_{1} \geq p_{1}^{e}$ implies $x_{1}\left(p_{1}\right) \leq e_{1}$. Suppose the statement in (i) were not true, i.e.,

$$
q_{1} x_{1}\left(p_{1}\right)+x_{2}\left(p_{1}\right)>q_{1} e_{1}+e_{2} .
$$

Then subtracting from this the equation $p_{1} x_{1}\left(p_{1}\right)+x_{2}\left(p_{1}\right)=p_{1} e_{1}+e_{2}$ yields $\left(q_{1}-p_{1}\right) x_{1}\left(p_{1}\right)>\left(q_{1}-p_{1}\right) e_{1}$, a contradiction since $p_{1} \leq q_{1}$ and $x_{1}\left(p_{1}\right) \leq e_{1}$.

The proof of part (ii) is similar and therefore omitted.

The final preliminary lemma establishes that an equilibrium allocation in our economy is always located between the agents' 'certainty lines'.

Lemma 3 Let the interior demand vectors $x^{A}$ and $x^{B}$ with prices $\left(p_{1}, p_{2}\right)$ be an equilibrium in $\mathcal{E}$. Then,

(i) if $x_{1}^{A}=x_{2}^{A}$, then $x_{1}^{B}=x_{2}^{B}$ and hence $w_{1}=w_{2}$;

(ii) if $x_{1}^{A}>x_{2}^{A}$, then $x_{1}^{B}>x_{2}^{B}$ and hence $w_{1}>w_{2}$;

(iii) if $x_{1}^{A}<x_{2}^{A}$, then $x_{1}^{B}<x_{2}^{B}$ and hence $w_{1}<w_{2}$.

Proof. For case (i), suppose that $x_{1}^{A}=x_{2}^{A}$. Then by (2), $\frac{p_{1}}{p_{2}}=\frac{\pi}{(1-\pi)}$. Again by (2), this implies $x_{1}^{B}=x_{2}^{B}$. For case (ii), suppose that $x_{1}^{A}>x_{2}^{A}$. Then $\left(u^{A}\right)^{\prime}\left(x_{1}^{A}\right)<\left(u^{A}\right)^{\prime}\left(x_{2}^{A}\right)$ and by (2), $\frac{p_{1}}{p_{2}}<\frac{\pi}{(1-\pi)}$. By (2) again, it follows that $\left(u^{B}\right)^{\prime}\left(x_{1}^{B}\right)<\left(u^{B}\right)^{\prime}\left(x_{2}^{B}\right)$. Therefore, $x_{1}^{B}>x_{2}^{B}$. Case (iii) is analogous. 


\section{The effect of risk aversion on equilibrium}

Consider two economies $\mathcal{E}=\left(u^{A}, u^{B}, e^{A}, e^{B}, \pi\right)$ and $\widetilde{\mathcal{E}}=\left(u^{\widetilde{A}}, u^{B}, e^{\widetilde{A}}, e^{B}, \pi\right)$ which differ only in the utility function of the first agent. More precisely, in $\widetilde{\mathcal{E}}$ agent $A$ is replaced by agent $\widetilde{A}$ with the same endowment $e^{\widetilde{A}}=e^{A}$ but with utility function $u^{\widetilde{A}}=k \circ u^{A}$, where $k$ is a strictly increasing and concave, twice differentiable function; hence, $k^{\prime}>0$ and $k^{\prime \prime}<0$ on the interior of the domain of $k$. Thus, $\widetilde{A}$ is more risk averse than $A$ according to the familiar Arrow-Pratt measure of risk aversion. The main purpose of this paper is to investigate the effect of increased risk aversion on the utility of agent $B$ through its effect on equilibrium. A direct comparison between the equilibrium utilities of $A$ and $\widetilde{A}$ is meaningless since the utility functions of these agents are not comparable with respect to magnitude.

In order to keep the presentation as simple as possible, we assume that the equilibria of $\mathcal{E}$ and $\widetilde{\mathcal{E}}$ are unique and interior. The uniqueness assumption renders it possible to make unambiguous comparisons between agent $B$ 's utility levels in equilibrium. ${ }^{3}$

The following lemma compares the offer curves of $A$ and $\widetilde{A}$ and therefore plays a crucial role in the proof of our main result.

Lemma 4 Let $p=\left(p_{1}, p_{2}\right)$ be a vector of positive prices and let $x=x(p)$ and $\widetilde{x}=\widetilde{x}(p)$ be the corresponding interior demands of $A$ and $\widetilde{A}$, respectively.

(i) If $x_{1}=x_{2}$, then $x_{1}=\widetilde{x}_{1}$ and $x_{2}=\widetilde{x}_{2}$.

(ii) If $x_{1}>x_{2}$, then $\widetilde{x}_{1}>\widetilde{x}_{2}, \widetilde{x}_{1}<x_{1}$ and $\widetilde{x}_{2}>x_{2}$.

(iii) If $x_{1}<x_{2}$, then $\widetilde{x}_{1}<\widetilde{x}_{2}, \widetilde{x}_{1}>x_{1}$ and $\widetilde{x}_{2}<x_{2}$.

Geometrically, this lemma can be summarized as follows: (i) the point on the offer curve of $A$ and the certainty line is also the point on the offer curve of $\widetilde{A}$ at the same prices; (ii) for a point on the offer curve of $A$ below the certainty line, the corresponding (that is, at the same prices) point on the offer curve of $\widetilde{A}$ lies also below the certainty line but closer to the certainty line, in the 'North-West' quadrant with respect to the original point; (ii) for

\footnotetext{
${ }^{3}$ Our conditions do not guarantee uniqueness. Familiar conditions for this like the gross substitutes condition (e.g., Takayama, 1985) are not satisfied. Our results below can be adapted to the case where the equilibria are not unique (this can occur) but then we would have to keep track of the equilibria that we are comparing.
} 
a point on the offer curve of $A$ above the certainty line, the corresponding (that is, at the same prices) point on the offer curve of $\widetilde{A}$ lies also above the certainty line but closer to the certainty line, in the 'South-East' quadrant with respect to the original point. This confirms our intuition with regard to the fact that $\widetilde{A}$ is more risk averse than $A$.

Proof of Lemma 4. By (2) we have

$$
\frac{p_{1}}{p_{2}}=\frac{\pi u^{\prime}\left(x_{1}\right)}{(1-\pi) u^{\prime}\left(x_{2}\right)}=\frac{\pi k^{\prime}\left(u\left(\widetilde{x}_{1}\right)\right) u^{\prime}\left(\widetilde{x}_{1}\right)}{(1-\pi) k^{\prime}\left(u\left(\widetilde{x}_{2}\right)\right) u^{\prime}\left(\widetilde{x}_{2}\right)}
$$

To show (i), let $x_{1}=x_{2}$. Then (5) implies $\widetilde{x}_{1}=\widetilde{x}_{2}$ and the budget restriction in (1) then implies $x_{1}=x_{2}=\widetilde{x}_{1}=\widetilde{x}_{2}$. To show (ii), let $x_{1}>x_{2}$. Then (5) implies $\widetilde{x}_{1}>\widetilde{x}_{2}$ and, moreover,

$$
\frac{u^{\prime}\left(x_{1}\right)}{u^{\prime}\left(x_{2}\right)}<\frac{u^{\prime}\left(\widetilde{x}_{1}\right)}{u^{\prime}\left(\widetilde{x}_{2}\right)}
$$

by concavity of $k$. Together with the budget restriction $p_{1} x_{1}+p_{2} x_{2}=p_{1} \tilde{x}_{1}+$ $p_{2} \tilde{x}_{2}\left(=p_{1} e_{1}^{A}+p_{2} e_{2}^{A}\right)$, this implies $x_{1}>\widetilde{x}_{1}$ and $x_{2}<\widetilde{x}_{2}$. The proof of (iii) is analogous.

Let $V$ denote the indirect utility function associated with $(1)$, i.e., $V(p)=$ $\pi u\left(x_{1}(p)\right)+(1-\pi) u\left(x_{2}(p)\right)$ for every vector of positive prices $p=\left(p_{1}, p_{2}\right)$. Then the partial derivatives of $V$ exist. The following lemma is concerned with the sign of these derivatives and establishes when utility increases or decreases along the offer curve.

Lemma 5 Consider an agent in $\mathcal{E}$ with utility function $u$, endowment $e$ and indirect utility function $V$. Let $x=x(p)$ be an interior demand. Then:

(i) If $x_{1}<e_{1}$, then $\frac{d V}{d p_{1}}>0$.

(ii) If $x_{1}=e_{1}$, then $\frac{d V}{d p_{1}}=0$.

(iii) If $x_{1}>e_{1}$, then $\frac{d V}{d p_{1}}<0$.

Proof. Without loss of generality set $p_{2}=1$. Then

$$
\frac{d V}{d p_{1}}=\pi u^{\prime}\left(x_{1}\right) \frac{d x_{1}}{d p_{1}}+(1-\pi) u^{\prime}\left(x_{2}\right)\left(e_{1}-x_{1}-p_{1} \frac{d x_{1}}{d p_{1}}\right) .
$$


By (2), this implies

$$
\frac{d V}{d p_{1}}=(1-\pi) u^{\prime}\left(x_{2}\right)\left(e_{1}-x_{1}\right) .
$$

This implies (i)-(iii).

The next result states, for a number of cases, how prices change in the equilibrium of $\widetilde{\mathcal{E}}$ compared to the equilibrium of $\mathcal{E}$.

Lemma 6 Let $c=\left(c_{1}^{A}, c_{2}^{A}, c_{1}^{B}, c_{2}^{B}\right)$ and $d=\left(d_{1}^{\widetilde{A}}, d_{2}^{\widetilde{A}}, d_{1}^{B}, d_{2}^{B}\right)$ be the unique, interior equilibrium allocations and $q$ and $\widetilde{q}$ the corresponding equilibrium prices of $\mathcal{E}$ and $\widetilde{\mathcal{E}}$, respectively, with $q_{2}=\widetilde{q}_{2}=1$. Then:

(i) If $c_{1}^{A}>c_{2}^{A}$ and $c_{1}^{A}>e_{1}^{A}$, then $\widetilde{q}_{1} \leq q_{1}$.

(ii) If $c_{1}^{A}>c_{2}^{A}$ and $c_{1}^{A} \leq e_{1}^{A}$, then $\widetilde{q}_{1} \leq q_{1}$.

(iii) If $c_{1}^{A}<c_{2}^{A}$ and $c_{1}^{A}>e_{1}^{A}$, then $\widetilde{q}_{1} \geq q_{1}$.

(iv) If $c_{1}^{A}<c_{2}^{A}$ and $c_{1}^{A} \leq e_{1}^{A}$, then $\widetilde{q}_{1} \geq q_{1}$.

Typical examples of cases (i)-(iv) in Lemma 6 are drawn in parts (i)-(iv) of Figure 1.

Proof of Lemma 6. We only prove (i), the other cases are analogous. Let $c_{1}^{A}>c_{2}^{A}$ and $c_{1}^{A}>e_{1}^{A}$. We normalize all price vectors by setting the state 2 price equal to 1 , and write $x\left(p_{1}\right)$ for the demand vector $x(p)$. We use $x^{A}\left(p_{1}\right)$ and $x^{B}\left(p_{1}\right)$ to denote demand vectors of $A$ and $B$, respectively.

We start with a useful observation. Let $p_{1}^{A}$ be the price such that $e^{A}$ $=x^{A}\left(p_{1}^{A}\right)$. Lemma $1(\mathrm{i})$ and $c_{1}^{A}>e_{1}^{A}$ imply $q_{1}<p_{1}^{A}$. Define $C$ to be the set

$$
\begin{array}{r}
C=\bigcup_{q_{1} \leq p_{1} \leq p_{1}^{A}}\left\{\left(x_{1}^{A}, x_{2}^{A}, x_{1}^{B}, x_{2}^{B}\right) \in \mathbb{R}^{4} \mid e_{1}^{A} \leq x_{1}^{A} \leq x_{1}^{A}\left(p_{1}\right),\right. \\
\left.p_{1} x_{1}^{A}+x_{2}^{A}=p_{1} e_{1}+e_{2}, x^{A}+x^{B}=e^{1}+e^{2}\right\} .
\end{array}
$$

In words, $C$ is the union of all line segments with as one endpoint the endowment point and as other endpoint a point on the offer curve of $A$ between $e$ and $c$ : observe that $e_{1}^{A}<x_{1}^{A}\left(p_{1}\right)<c_{1}^{A}$ for every $q_{1}<p_{1}<p_{1}^{A}$ by Lemma 1. Also, $C$ is a subset of feasible allocations since, by Lemma 2(i), every 


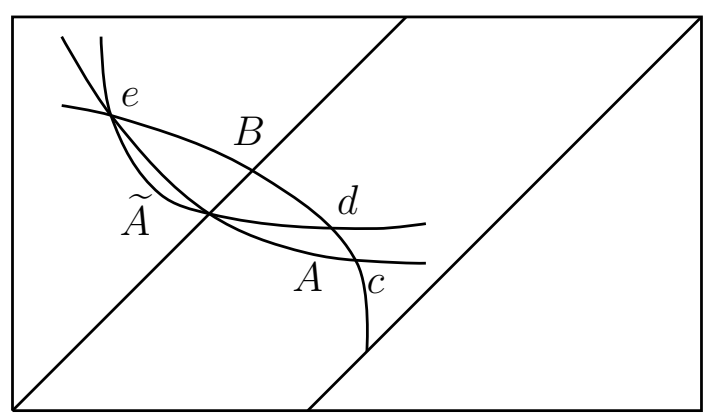

(i)

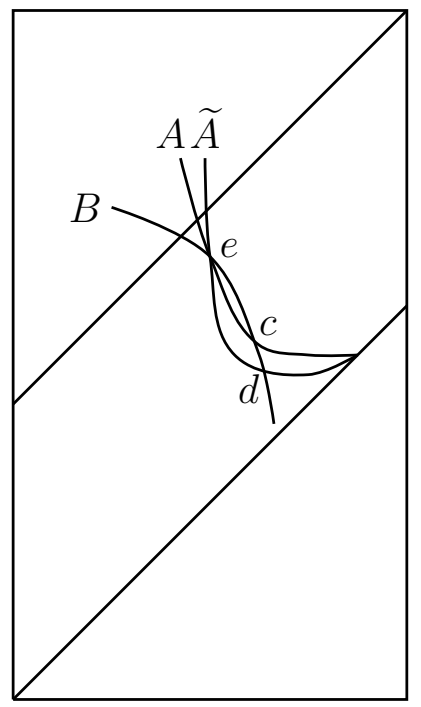

(iii)

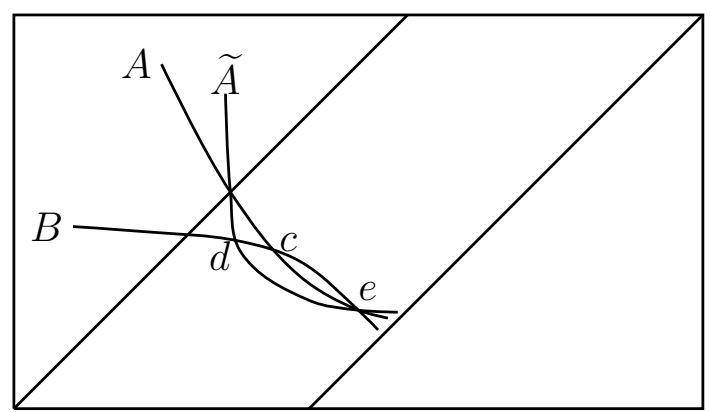

(ii)

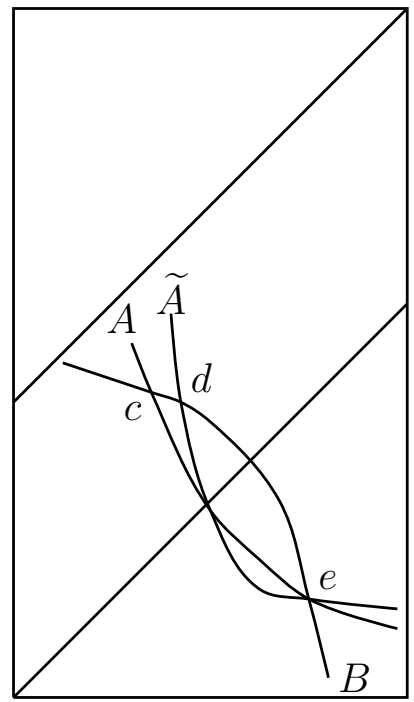

(iv)

Figure 1: Panels (i)-(iv) sketch instances of the cases (i)-(iv) in Lemma 6. In each case an Edgeworth box is drawn with the origin for $A$ and $\widetilde{A}$ at the lower left point and the origin for $B$ at the upper right point. Also the agents' certainty lines are drawn. In cases (i) and (iv) the endowment point $e$ can also be located at the other side of $A$ 's certainty line, but that does not make an essential difference. Similarly, in cases (ii) and (iii), e could be located on the other side of $B$ 's certainty line. In all four panels, three offer curves are drawn, and the equilibrium allocations $c$ and $d$ are the points of intersection. 
element of $C$ is below the budget line through $e$ and $c$, and by the previous observation, has first coordinate between $e_{1}^{A}$ and $c_{1}^{A}$. It can be verified that $C$ is a closed set with as boundary the union of the feasible allocations on the offer curve of $A$ below the budget line through $e$ and $c$ in the Edgeworth box, and the line segment between $e$ and $c$. In fact, $C$ is the set between the offer curve of $A$ and the line segment connecting $e$ and $c$, but our definition of $C$ turns out to be useful below.

We claim that $e$ and $c$ are the only feasible allocations in $C$ on the offer curve of $B$. Suppose not, and let $y=\left(y^{A}, y^{B}\right)$ be another feasible allocation in $C$ on the offer curve of $B$. Let $p_{1}^{B}$ such that $x^{B}\left(p_{1}^{B}\right)=e^{B}$. By Lemma $1, p_{1}^{B}<q_{1}$. Since $y \in C$ and, thus, $y_{1}^{B}<e_{1}^{B}$ and $y_{2}^{B}>e_{2}^{B}$, Lemma 2 and Lemma 1 imply that $y^{B}=x^{B}\left(p_{1}^{y}\right)$ for some price $p_{1}^{y}>q_{1}$. By Lemma 1 (ii), it follows in particular that $x_{2}^{B}\left(p_{1}\right)>c_{2}^{B}>e_{2}^{B}$ for all $p_{1} \geq p_{1}^{y}$. Choose $p_{1}^{z}>\max \left\{p_{1}^{y}, p_{1}^{A}\right\}$, then the feasible allocation $z$ with $z^{B}=x^{B}\left(p_{1}^{z}\right)$ is not in $C$. Since $C$ is a closed set and the offer curve of $B$ a continuous curve, this curve must intersect the boundary of $C$ at a point $v$ for some price between $p_{1}^{y}$ and $p_{1}^{z}$. Since $v$ cannot be a point on the line segment connecting $e$ and $c$, it must be a point on the offer curve of $A$ unequal to $e$ or $c$. But then, $v$ is an equilibrium allocation, contradicting our assumption that equilibrium is unique.

Now suppose, contrary to what we wish to prove, that $\widetilde{q}_{1}>q_{1}$. Lemma 3 and $c_{1}^{A}>c_{2}^{A}$ imply $w_{1}>w_{2}$, and therefore, by Lemma 3 again, $d_{1}^{\widetilde{A}}>d_{2}^{\widetilde{A}}$. Since $d$ is on the offer curve of $B, \widetilde{q}_{1}>q_{1}>p_{1}^{B}$ and Lemma 1(ii) imply $d_{2}^{B}>$ $e_{2}^{B}$ and, thus, $d_{1}^{B}<e_{1}^{B}$. Consider the feasible allocation $x$ with $x^{A}=x^{A}\left(\widetilde{q}_{1}\right)$, which is located on the offer curve of $A$ and the budget line through $e$ and $d$. If $x$ is on the same side of $d$ as $e$ is, i.e., if $x_{1}^{A} \leq d_{1}^{\widetilde{A}}$, then consider two cases. If $x_{1}^{A}>x_{1}^{B}$, then, by Lemma 4(ii), $d^{\widetilde{A}}$ has first coordinate smaller than $x_{1}^{A}$, a contradiction. If $x_{1}^{A} \leq x_{1}^{B}$, then by Lemma $4(\mathrm{i})$ or (iii), $d_{1}^{\widetilde{A}} \leq d_{2}^{\widetilde{A}}$, again a contradiction. Hence, we must have $x_{1}^{A}>d_{1}^{\widetilde{A}}$. Then $\widetilde{q}_{1} \leq p_{1}^{A}$ since otherwise $x_{1}^{A}<e_{1}^{A}<d_{1}^{A}$ by Lemma $1(\mathrm{i})$, a contradiction. Hence $q_{1}<\widetilde{q}_{1} \leq p_{1}^{A}$, which implies that $d$ is in the set $C$, contradicting our claim above.

Thus, we must have $\widetilde{q}_{1} \leq q_{1}$.

Let $q$ and $\widetilde{q}$ be the equilibrium prices in $\mathcal{E}$ and $\widetilde{\mathcal{E}}$, respectively. Let $V^{B}$ denote the indirect utility function of agent $B$. We say that risk aversion (of the opponent) benefits agent $B$ if $V^{B}(\widetilde{q}) \geq V^{B}(q)$ and risk aversion (of the opponent) hurts agent $B$ if $V^{B}(\widetilde{q}) \leq V^{B}(q)$. The following theorem answers 
the question when risk aversion benefits or hurts agent $B$.

Theorem 1 Let $c=\left(c_{1}^{A}, c_{2}^{A}, c_{1}^{B}, c_{2}^{B}\right)$ and $d=\left(d_{1}^{\widetilde{A}}, d_{2}^{\widetilde{A}}, d_{1}^{B}, d_{2}^{B}\right)$ be the unique, interior equilibrium allocations and $q$ and $\widetilde{q}$ the corresponding equilibrium prices of $\mathcal{E}$ and $\widetilde{\mathcal{E}}$. Consider the following exclusive cases:

(i) $w_{1}=w_{2}$.

(ii) $w_{1}>w_{2}$ and

$$
\begin{aligned}
& \text { (ii.a) } e_{1}^{A} \leq e_{2}^{A} . \\
& \text { (ii.b) } e_{1}^{A}>e_{2}^{A}, c_{1}^{A} \leq e_{1}^{A} . \\
& \text { (ii.c) } e_{1}^{A}>e_{2}^{A}, c_{1}^{A}>e_{1}^{A}, d_{1}^{B} \leq e_{1}^{B} .
\end{aligned}
$$

(iii) $w_{1}<w_{2}$ and

$$
\begin{aligned}
& \text { (iii.a) } e_{1}^{A} \geq e_{2}^{A} . \\
& \text { (iii.b) } e_{1}^{A}<e_{2}^{A}, c_{1}^{A} \geq e_{1}^{A} . \\
& \text { (iii.c) } e_{1}^{A}<e_{2}^{A}, c_{1}^{A}<e_{1}^{A}, d_{1}^{B} \geq e_{1}^{B} .
\end{aligned}
$$

Then risk aversion benefits agent $B$ in the cases (ii.b) and (iii.b). In case $(i), q=\widetilde{q}$ and $c=d$, so $V^{B}(q)=V^{B}(\widetilde{q})$. In all other cases, risk aversion hurts agent $B$.

Proof. Case (i) follows directly from Lemma 3 and Lemma 4(i).

For case (ii.a), it follows from Lemma 3 and Lemma $6(\mathrm{i})$ that $\widetilde{q}_{1} \leq q_{1}$. From Lemma 3 again and from Lemma $5(\mathrm{i}), V^{B}(\widetilde{q}) \leq V^{B}(q)$, so risk aversion hurts $B$.

For case (ii.b), by Lemma 3 and Lemma 6(ii), $\widetilde{q}_{1} \leq q_{1}$. By Lemma 5(ii),(iii), $V^{B}(\widetilde{q}) \geq V^{B}(q)$, so risk aversion benefits $B$.

For case (ii.c), by Lemma 3 and Lemma $6(\mathrm{i}), \widetilde{q}_{1} \leq q_{1}$. By Lemma 5(i), $V^{B}(\widetilde{q}) \leq V^{B}(q)$, so risk aversion hurts $B$.

The analogous proofs for cases (iii.a)-(iii.c) are omitted.

Theorem 1 can be summarized in a non-technical way as follows. This summary also provides a good intuition for the results. If agent $A$ is replaced by a more risk averse agent $\widetilde{A}$, then the equilibrium allocation moves closer to agent $A$ 's (or $\widetilde{A}$ 's) certainty line, as is intuitive. This movement takes 
place along agent $B$ 's offer curve. If the equilibrium allocation moves away from the endowment point $e$, then this is beneficial to agent $B$, as follows from Lemma 5. If it moves towards $e$, then this hurts agent $B$. The latter observation also explains why Theorem 1 is not exhaustive. Cases (ii.c) and (iii.c), where the equilibrium allocation indeed moves towards the endowment point, are restricted by the condition that the equilibrium allocation should not actually cross the endowment point, since in that case, agent $B$ 's utility starts to increase again, so that the finally resulting effect is ambiguous. Example 1 below shows that this can indeed happen.

Cases (ii.b) and (iii.b) of Theorem 1 are illustrated in Panels (ii) and (iii) of Figure 1, respectively. In both cases the movement from $c$ to $d$ along the offer curve of $B$ is away from the endowment point $e$ : this benefits agent $B$. Cases (ii.a) and (iii.a) of Theorem 1 are illustrated in Panels (i) and (iv) of Figure 1, respectively. In both cases the movement from $c$ to $d$ along the offer curve of $B$ is towards the endowment point $e$ : this hurts agent $B$.

Example 1 Let agent $A$ have utility function $u^{A}(t)=\ln (t+1)$ and endowment $e^{A}=\left(\frac{11}{10}, \frac{13}{20}\right)$. Agent $B$ has utility function $u^{B}(t)=\ln t$ and endowment $\left(\frac{19}{10}, \frac{27}{20}\right)$. So $w_{1}=3$ and $w_{2}=2$. Let $\pi=\frac{1}{2}$. Let $\widetilde{A}$ be a more risk averse agent, with utility function $u^{\widetilde{A}}(t)=\ln t$. Let $c$ and $d$ be the equilibrium allocations in $\mathcal{E}$ and $\widetilde{\mathcal{E}}$, respectively. It is straightforward to compute that $c^{B}=\left(\frac{37}{20}, \frac{111}{80}\right)$ and $d^{B}=\left(\frac{157}{80}, \frac{157}{120}\right)$. Then $c_{1}^{B}<e_{1}^{B}<d_{1}^{B}$ and $B$ 's expected utility at $d(\approx 0.4715)$ is higher than at $c(\approx 0.4713)$. Theorem 1 does not apply here, since the last condition in case (ii.c) is not fulfilled: by going from $c$ to $d$ along $B$ 's offer curve, endowment point $e$ is crossed.

Consider, next, an agent $\bar{A}$ with utility function $u^{\bar{A}}(t)=\ln \left(t+\frac{1}{5}\right)$, which

implies that $\bar{A}$ is more risk averse than $A$ (but less so than $\widetilde{A}$ ). Now the new equilibrium allocation is the point $\bar{d}$ with $\bar{d}^{B}=\left(\frac{85}{44}, \frac{85}{64}\right)$, with expected utility approximately equal to 0.4711 , hence smaller than at $c$. We still have $c_{1}^{B}<e_{1}^{B}<\bar{d}_{1}^{B}$, so that Theorem 1 again does not apply.

\section{Concluding remarks}

Extending our model and results to more than two agents and/or more than two states may be quite hard, due to the many different possible configurations of endowments and equilibrium allocations. An additional complication in case of more than two agents is that agents' utilities may be affected in 
different directions if one agent is replaced by a more risk averse agent. For particular choices of utility functions (e.g., linear risk tolerance functions) it may be possible to obtain some results, but this is left for further research.

To the best of our knowledge, a comparative static study with respect to risk aversion in financial equilibrium models like the one in this paper, has not explicitly been carried out before. The impact of increased risk aversion has been studied before in the related area of game theory. See, for instance, Kihlstrom et al. (1981) and Köbberling and Peters (2003) for bargaining games, and Berden and Peters (2005) for two-person noncooperative games.

\section{References}

Berden, C., and H. Peters (2005): "On the effect of risk aversion in bimatrix games," forthcoming in Theory and Decision.

Kihlstrom, R.E., A.E. Roth, and D. Schmeidler (1981): "Risk aversion and solutions to Nash's bargaining problem," in: O. Moeschlin and D. Pallaschke (eds.), Game Theory and Mathematical Economics. North Holland, Amsterdam.

Köbberling, V., and H. Peters (2003): "The effect of decision weights in bargaining problems," Journal of Economic Theory, 110, 154-175.

LeRoy, S.F., and J. Werner (2001): Principles of Financial Economics. Cambridge University Press, Cambridge UK.

Takayama, A. (1985): Mathematical Economics. Cambridge University Press, Cambridge UK. 